\title{
Erratum to: The Effects of Composition and Microstructure on the Thermal Conductivity of Liquid-Phase-Sintered W-Cu
}

\author{
JOHN L. JOHNSON, SEONG JIN PARK, YOUNG-SAM KWON, \\ and RANDALL M. GERMAN
}

DOI: $10.1007 / \mathrm{s} 11661-010-0312-5$

(C) The Minerals, Metals \& Materials Society and ASM International 2010

\section{Erratum to: METALLURGICAL AND MATERIALS TRANSACTIONS A, Vol. 41A, No. 6, pp. 1564-1572 DOI 10.1007/s11661-010-0210-x}

FIGURE 11 is incorrect as it appears in the original article due to a typesetting error. The typesetter regrets the error. Following is the correct Figure 11:

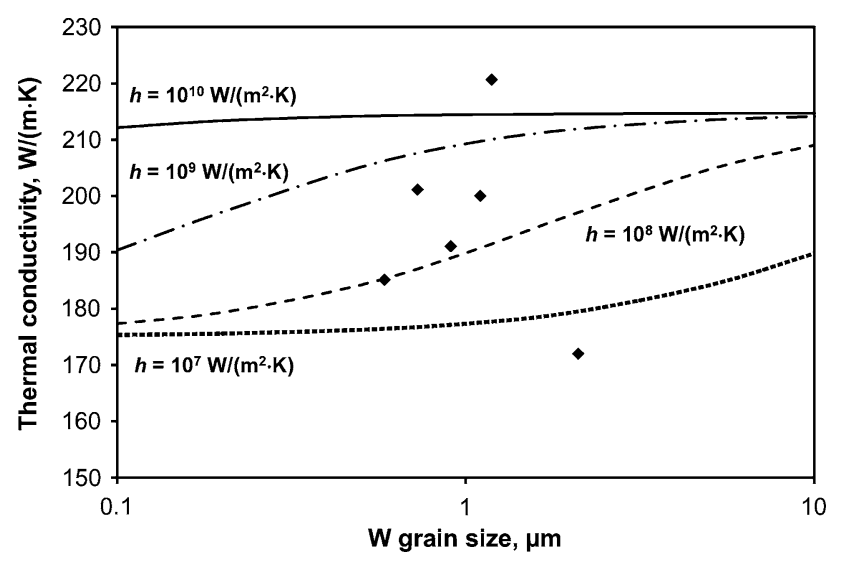

Fig. 11-Effect of grain size on the thermal conductivity of pure, pore-free $\mathrm{W}-15 \mathrm{Cu}$ with a contiguity of 0.35 for different thermal boundary conductances, $h$. Experimental data from Table I and a previous study ${ }^{[33]}$ are given for comparison.
JOHN L. JOHNSON, R\&D Director, is with ATI Engineered Products, Huntsville, AL 35806. Contact e-mail: John.Johnson@ ATImetals.com SEONG JIN PARK, Assistant Professor, is with the Department of Mechanical Engineering, Pohang University of Science and Technology (POSTECH), Pohang, Gyungbuk, 790-784, S. Korea. YOUNG-SAM KWON, President, is with CetaTech, Inc., Sacheon, Gyungnam, 664-953, S. Korea. RANDALL M. GERMAN, Associate Dean, is with the College of Engineering, San Diego State University, San Diego, CA 92182-1326.

The online version of the original article can be found under doi: 10.1007/s11661-010-0210-x.

Article published online May 14, 2010 